\title{
Lymphocyte subsets in 32 patients with multisystem inflammatory syndrome in children (MIS-C)
}

\author{
Magdalena Okarska-Napierała ${ }^{1}$, Joanna Mańdziuk ${ }^{1}$, Wojciech Feleszko ${ }^{1}$, Anna \\ Stelmaszczyk-Emmel ${ }^{1}$, Mariusz Panczyk ${ }^{1}$, Urszula Demkow ${ }^{1}$, and Ernest Kuchar ${ }^{1}$ \\ ${ }^{1}$ Medical University of Warsaw
}

May 31, 2021

\begin{abstract}
BACKGROUND: Lymphopenia is a hallmark of multisystem inflammatory syndrome in children (MIS-C). We aimed to characterize lymphocyte subsets' shifts and their correlations with other severity markers of MIS-C. METHODS: In this prospective cross-sectional study, we performed peripheral lymphocyte phenotyping in 32 patients with MIS-C. We analyzed lymphocyte subsets at three time-points of the disease: the acute (A), convalescent (B), and recovery (C) phases. Based on age-normalized lymphocyte counts, we distinguished two groups of patients: "the mild" and "the severe". In addition, we examined differences between these groups regarding other severity markers. RESULTS: In phase A, $84 \%$ of children had lymphopenia. Decreased absolute counts of CD3, CD4, and CD8 cells were observed in, respectively, $88 \%, 72 \%$, and $84 \%$ of patients. The natural killer cells were decreased in $63 \%$ and CD19 in 59\% of children. "The severe" group had significantly higher procalcitonin and troponin I levels and lower platelets and albumin. Moreover, "the severe" group had hypotension more frequently ( $73 \%$ vs. $20 \%$, $\mathrm{p}=0.008$ ). In phase B, all lymphocyte counts increased, and $32 \%$ of children had lymphocytosis. The increase of CD3, CD4, and CD8 counts correlated with some laboratory severity markers (hemoglobin, procalcitonin, D-dimer, lactate dehydrogenase, $\mathrm{N}$-terminal prohormone of brain natriuretic peptide, albumin), but not with steroid use. In phase C, most children had normal lymphocyte counts. CONCLUSIONS: Substantial shifts in lymphocyte counts during MIS-C apply most to T lymphocytes and correlate with the disease severity markers, particularly hypotension prevalence. A proportion of children with MIS-C develops transient lymphocytosis during convalescence.
\end{abstract}

\section{Hosted file}

MainDocument.docx available at https://authorea.com/users/416793/articles/524195-1ymphocytesubsets-in-32-patients-with-multisystem-inflammatory-syndrome-in-children-mis-c 


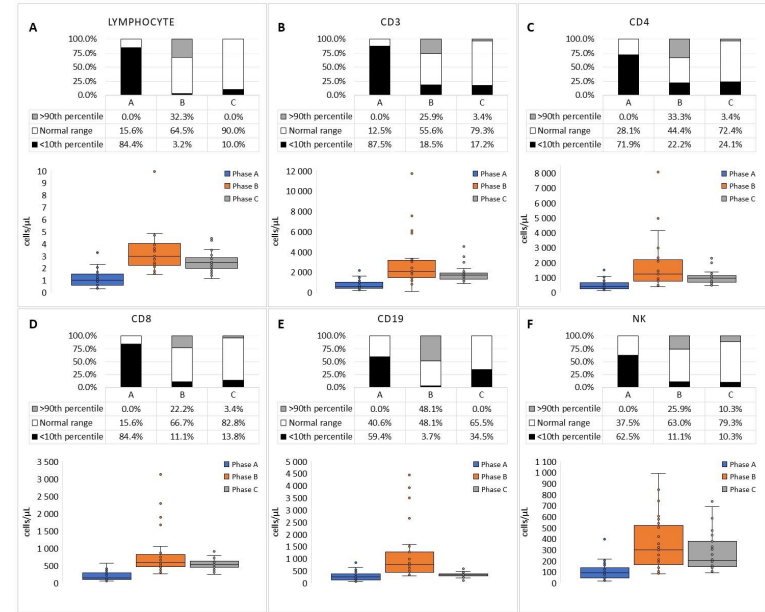




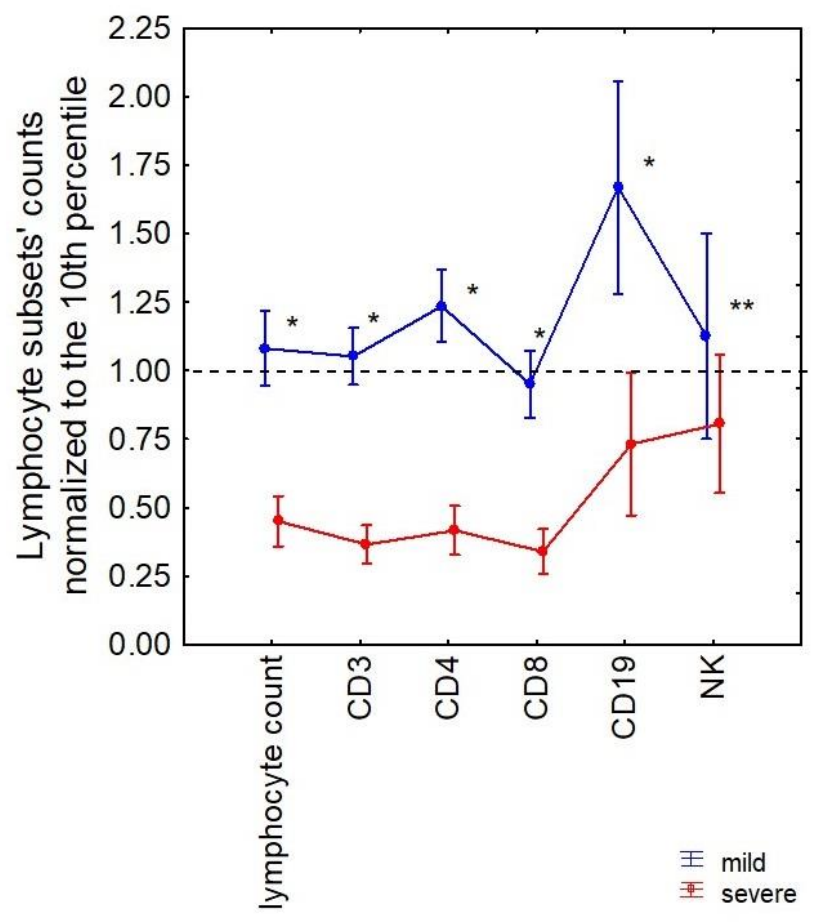




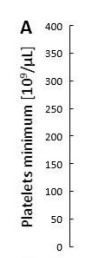

C

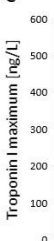
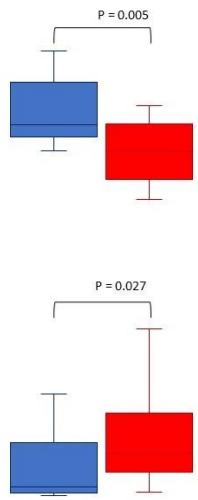
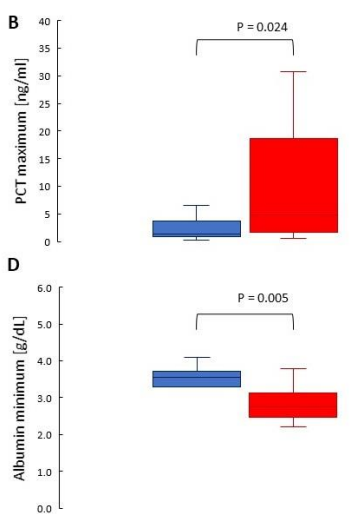

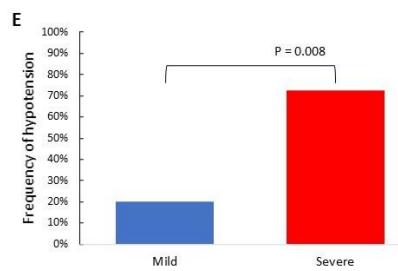

Severe

\section{Hosted file}

Table 1.docx available at https://authorea.com/users/416793/articles/524195-lymphocytesubsets-in-32-patients-with-multisystem-inflammatory-syndrome-in-children-mis-c

\section{Hosted file}

Table 2.docx available at https://authorea.com/users/416793/articles/524195-lymphocytesubsets-in-32-patients-with-multisystem-inflammatory-syndrome-in-children-mis-c 